\title{
Experimental Study on the Characteristics of Fire Smoke Movement in Ultra Thin and Tall Atriums by Hot Smoke Test
}

\author{
Hao Zhang ${ }^{1,2}$, Cuifeng $\mathrm{Du}^{1,}$, , Jingji $\mathrm{Li}^{2}$, Jian Chen ${ }^{2}$ and Hongwen $\mathrm{Li}^{2}$ \\ ${ }^{1}$ University of Science and Technology Beijing, Department of Safety Science and Engineering,100083 Beijing, China \\ ${ }^{2}$ China Academy of Building Research, Insititute of Building Fire Research, 100013 Beijing, China
}

\begin{abstract}
The characteristics of smoke natural filling in ultra thin and tall atriums were investigated by hot smoke test method. For the fire located on the atrium ground, the smoke touched the side wall first and then extended both upwards and downwards. The smoke plume rising velocity variation can be divided into four stages, different from the normal law in large spaces. In the very early stage of natural filling, the smoke concentration near the height of wall touching point was highest and maintained at a high level in the whole process. The linear trend of temperature increasing in plume center above the height of touching point was broken, far less than the theoretical predictions, which verified the enhancement effect of boundary heat exchange caused by plume restriction. The variation tendencies of smoke density and temperature were similar during the hot smoke test,and there existed a good linear relation between these two parameters. The height-width ratio was calculated as 3.2 averagely by the test results when smoke plume would likely touch atrium walls, and it was very close to the theoretically derived value. This ratio can be used as the definition condition for ultra thin and tall atriums.
\end{abstract}

\section{Introduction}

China has become the new center of skyscrapers after USA, Japan and West Asia. It is estimated that by 2022, the total number of super high-rise buildings in China will reach 1318, almost 2.5 times of USA [1]. Along with the development of super high-rise buildings, a distinctive atrium form appears, which has slim body and small area but large height-usually over $50 \mathrm{~m}$ or even more than $100 \mathrm{~m}$.

Due to the flexible forms, the atriums' classification is extremely complex. Especially, the geometry of atriums will affect the development and spread of fire and smoke, but there is still no clear and uniform method for its division. Based on the investigation of Hong Kong atriums, Chow proposed that the atrium can be divided into three types: three-dimensional, flat and thin in accordance with the ratio of length to width to height[2][3]. J.H.Klote and J.A.Milke defined the atrium aspect ratio as $\mathrm{H}^{2} / \mathrm{A}$ [4]. In NFPA92 the coefficient $\mathrm{A} / \mathrm{H}^{2}$ is used as the limiting application condition of the smoke layer height calculation formula in atriums [5]. T. Naruse and S. Sugahara conducted a survey of 18 different atrium buildings in Japan [6]. Based on statistical data, three different types of atriums were roughly defined: shopping mall type, approximate three-dimensional type and thin-tall type. The aspect ratio of thin-tall atriums was mainly concentrated at about 10. Liu Fang investigated 30 atriums in China, using the shape factor $\left(\mathrm{A} / \mathrm{H}^{2}\right.$, the atrium construction area divided by the square of the height of the atrium) to reflect the geometry of the atrium, and considered the atrium with a shape factor of less than 0.4 was thin type [7].

Through the investigation of the atriums in Chinese super high-rise buildings, the shape factor of the ultra thin and tall atriums described in this article is very small, basically not larger than 0.1 , and significantly different with the thin atriums described by those predecessors. Compared with flat and stereo atriums, the characteristics of fire smoke movement and smoke control strategies in ultra thin and tall atriums show obvious peculiarities [8]:

(1) The development of fire smoke plume is restricted due to wall surfaces, the rising path of plume is long, the amount of entrained cold air is large, and there is heat and cold exchange between smoke and wall surfaces during the ascending process.

(2) The stack effect increases with the ascend of atrium's height, thus it will be much more violent in ultra thin and tall atriums than in normal atriums when fire occurs.

(3) Smoke control has much more difficulty as ultra thin and tall atriums connect more floors and usually connect adjacent areas. It is not easy to control the smoke spread path as well as exhaust smoke effectively.

(4) The presence of thick hot air layer in the headspace of the atrium, coupled with its large height and long plume path, will result in more pronounced stratification effect that increases the difficulty of smoke detection and extraction.

Some scholars have paid attention to the particularity of fire smoke management in thin-type atriums and

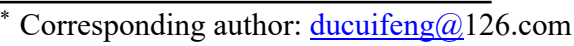


carried out some research work. H. Satoh and O. Sugawa studied the temperature rise and ventilation rate in high and narrow atrium space and proposed a simple prediction model [9]. Chow used the regional model to analyze the smoke filling time of atriums with different geometric configurations and evaluate the smoke exhaust performance [2,10]. Liu Fang conducted tests in a thin atrium scaled model with shape factor of 0.366 and proposed that the shape factor of atriums had significant impact on smoke filling process in addition to fire heat release rate and only the volume of atriums was considered in smoke management system design was unreasonable [7]. Some other researchers carried out analysis of smoke extraction method with CFD for specific thin and tall atriums. However, there is not clear and definite design guideline and systematic public research results for ultra thin and tall atriums at present, even the definition is still vague. The lack of basic research results of smoke spread and development laws in ultra thin and tall atriums has restricted their smoke control design, test and assessment as well as for the super high-rise buildings they belong to.

Hot smoke test is an effective method for fire science research and building smoke control system evaluation. Australia, Belgium, China and some other countries have issued hot smoke test standards [11-13]. In this paper, hot smoke tests are designed according to GA/T 9992012 to obtain index data such as smoke temperature, velocity, density distribution and imaging data in ultra thin and tall atriums, which can lay a theoretical foundation for further optimization of smoke control strategies.

\section{Hot smoke test}

\subsection{Test site}

The experiment selected the atrium in TVCC, China Central Television, as the test site. TVCC is a multifunctional high-rise building that consists of a tower and a podium, including a five-star hotel (the test area), theater and exhibition facilities. The highest elevation of the building is $159.0 \mathrm{~m}$ and the standard floor height is $4.0 \mathrm{~m}$. It should be specially pointed out that the building had a serious fire accident on February 9, 2009, causing huge economic losses and serious social impact [14].

The hotel of TVCC has an ultra thin and tall atrium with floor area of around $1260 \mathrm{~m}^{2}$ and height of about 96 $\mathrm{m}$. The atrium's volume exceeds $1.3 \times 105 \mathrm{~m}^{3}$, connecting F5 F26 (F26 is divided into a, b, c, d four parts from bottom to top). The building's present smoke control system consists of top smoke extraction (F26a), middle smoke extraction (F10) and lower air supply (F7). Infrared beam smoke detectors are installed at the height of F26b and between the atrium F8 and F9. Point type smoke detectors are installed in the corridors and rooms in all floors.
Hot smoke tests were carried out according to GA/T 999-2012 [12]. Ethanol of $95 \% \mathrm{vol}$ and the $2 \times \mathrm{A} 1$ tray size was used with a steady heat release of about $700 \mathrm{~kW}$. The test apparatus is shown in Fig. 1. There was a large pool in the center of the ground floor (F5) and the fire was located on the east side of the floor between the pool and the service desk, as shown in Fig. 2.

The measuring instrument used in hot smoke test included thermocouple, temperature recorder, infrared thermal imager, DV, camera, aspirating smoke detection system and the overall arrangement program is shown in Figure. 3. Three bunches of temperature measuring sensors were set in the atrium and respectively located directly above the fire, near the southwest corridor and near the southeast corridor. Aspirating smoke detection system was able to do quantitative analysis of smoke concentration by collecting smoke samples. PVC sampling pipes were fixed by horizontal installation and vertical installation: the former one extended pipe $2.5 \mathrm{~m}$ away from the corridor at F11, F18 and F26a, and set four sampling holes with distance of $10 \mathrm{~cm}$ and diameter of $3.5 \mathrm{~mm}$ from outside to inside; the latter one drooped a pipe from F26a to F22 and set a sampling hole on each floor with diameter of $3.5 \mathrm{~mm}$. The two installation methods are shown in Fig. 4 (a), (b) below.

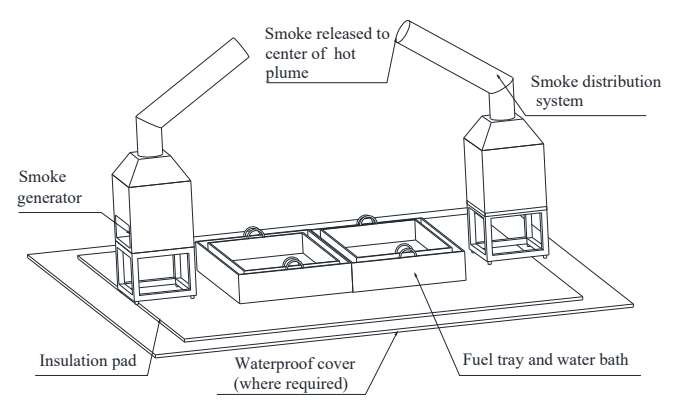

Fig. 1. Schematic diagram of hot smoke test apparatus.

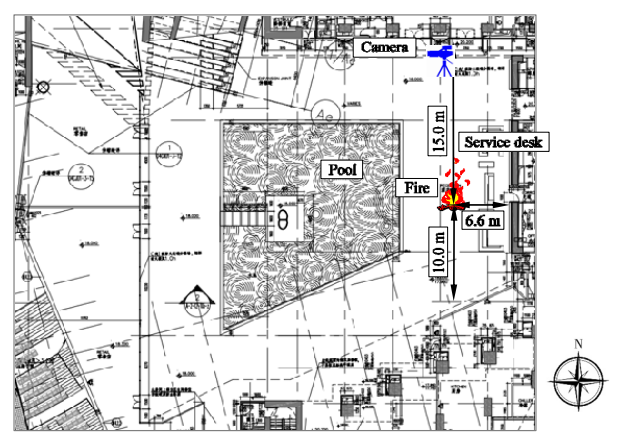

Fig. 2. Position of the fire. 


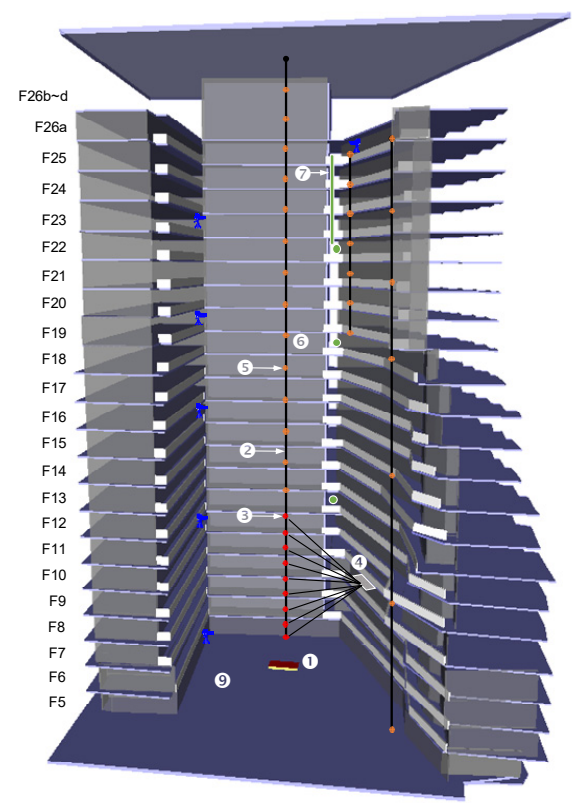

1-Fuel tray;2-life line;3-K type thermal couple; 4- Data acquisition host (compensating wire included);5-Tempreture recorder;6-Horizontal smoke sampling point;7-Vertical smoke sampling pipe;8-DV;9-Infrared thermal imager

Fig. 3. General layout of measuring points.

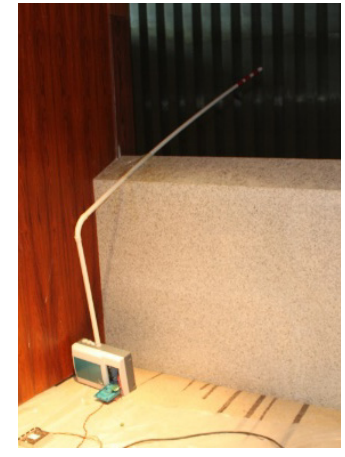

(a) Horizontal pipe

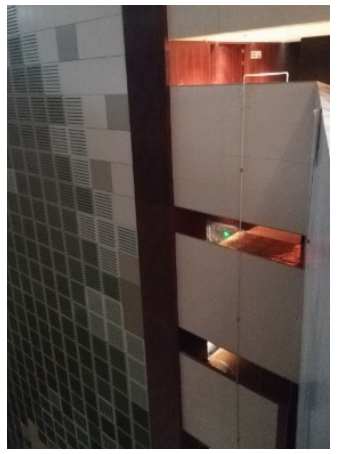

(b) Vertical pipe
Fig. 4. Installation of the smoke density measuring equipment.

Within $600 \mathrm{~s}$ after ignition (fuming) in the tests, the smoke naturally filled and spread in the atrium. The top extraction fans were activated at $600 \mathrm{~s}$.

\subsection{Environmental parameters}

The environmental parameters were recorded right before the test, which are shown in Table 1.

Table 1. Environmental parameters during the test period.

\begin{tabular}{|c|c|c|}
\hline $\begin{array}{c}\text { Environmental } \\
\text { parameters }\end{array}$ & Outside TVCC & F5 of TVCC \\
\hline Temperature $\left({ }^{\circ} \mathrm{C}\right)$ & 29.63 & 26.42 \\
\hline $\begin{array}{c}\text { Atmospheric pressure } \\
(\mathrm{kPa})\end{array}$ & 100.2 & 99.9 \\
\hline $\begin{array}{c}\text { Velocity (m/s) } \\
\text { Relative humidity } \\
(\% \mathrm{RH})\end{array}$ & 53.34 & 0.02 \\
\hline
\end{tabular}

\subsection{Temperature of test fire}

Pool fire combustion status is shown in Fig. 5. In the experiment, the temperature field near the fire was measured by infrared thermal imager. The temperature of the liquid fuel surface was basically $720 \sim 760{ }^{\circ} \mathrm{C}$, and that of the smoke at the chimney outlet was about $90{ }^{\circ} \mathrm{C}$. The smoke spread status is shown in Fig. 6.

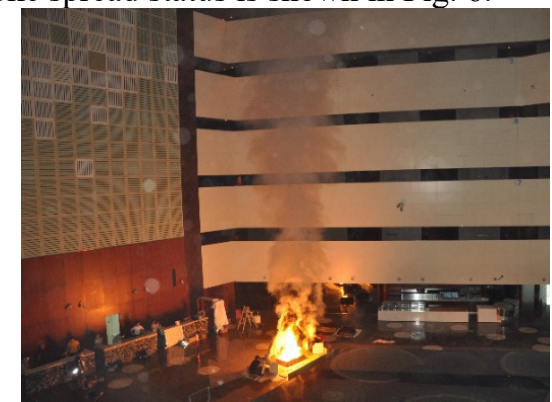

Fig. 5. Combustion status of the fire.

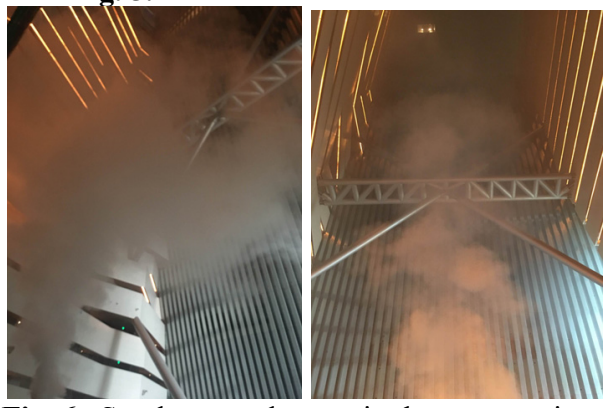

Fig. 6. Smoke spread status in the upper atrium.

\subsection{Smoke spread route in atrium space}

To avoid subjectivity judging of human eyes, the test reported the dynamic changes of alarm time and location of point type smoke detectors in the building to reflect the smoke spread path. Since smoke detectors had same alarm thresholds, this method had nearly uniform criteria for analyzing smoke spread extent. Fig. 7 shows alarm conditions of smoke detectors (including infrared beam detectors at F26b) at several typical moments.

The white fine particles produced by the smoldering smoke cake rose rapidly along with hot plume and reached the ceiling of F26d in about 3 minutes. Due to the deviation of fire location to the south, the smoke plume first contacted the south atrium wall at the height of about F20, and then contacted the north wall at F25.Then smoke spread showed two ways of expansion trend-up and down, i.e., the adjacent floors above and below the wall touching height were still first affected by smoke despite of the existence of smoke barriers.

Smoke detectors of F17 F25 at the south corridors alarmed within $300 \mathrm{~s}$. After the smoke plume rose to the ceiling, it simultaneously subsided and spread circumferentially, which showed that the alarm number of smoke detectors increased rapidly and regularly and the top smoke concentration rose leading to continuous visibility decrease of top floor.

\section{Results and discussions}



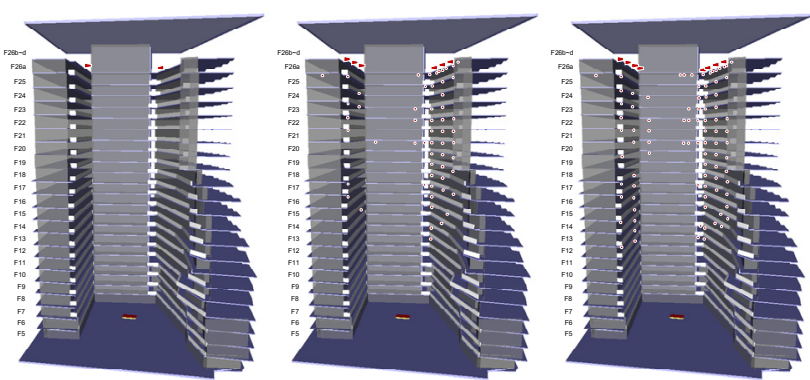

(a) $\mathrm{t}=180 \mathrm{~s}$

(b) $\mathrm{t}=450 \mathrm{~s}$

(c) $\mathrm{t}=600 \mathrm{~s}$

Fig. 7. Smoke spread conditions at typical moments.

\subsection{Smoke plume rising velocity}

The time for ethanol combustion to reach a stable HRR of $0.7 \mathrm{MW}$ is about $61 \mathrm{~s}$. Average rising velocity of smoke plume and time to reach different floors were monitored above 40m during the test, as shown in Fig.8. The rising velocity of smoke plume front started to decrease before the height of $40 \mathrm{~m}$, rose after plume edge contacted the side wall, and rapidly reduced again near top due to the ceiling stagnation. It can be seen that due to the wall effect in the ultra thin and tall atrium, the overall trend of the smoke plume rising velocity with the rising height can be divided into four stages: risingdecreasing-rising-decreasing.

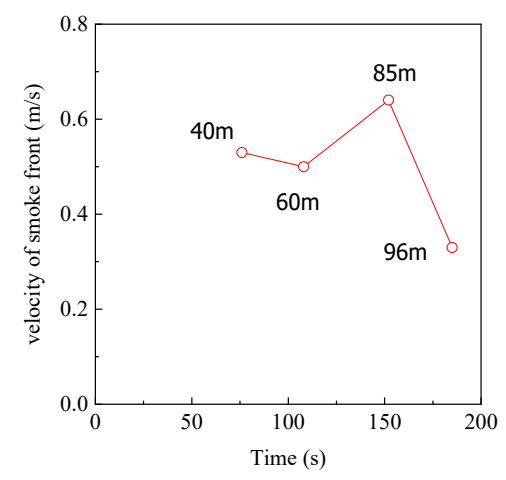

Fig. 8. Smoke plume rising velocity.

\subsection{Temperature distribution in the atrium}

In the ultra thin and tall atrium, the upper floors are usually more dangerous, so the temperature data above $18 \mathrm{~m}$ are plotted in Fig. 9. In addition, the data obtained from the other two strings of temperature measuring points near corridors is plotted in Fig. 10(a), (b) respectively.

Viewing from Fig. 9, 10, the temperature distribution was non-uniform in the atrium before the start of test, and there existed a temperature difference of $2 \sim 3{ }^{\circ} \mathrm{C}$ vertically. For the temperature right above the fire, the difference from top to bottom reached its maximum at around $120 \mathrm{~s}$ after ignition. With the rising of hot smoke, the temperature difference was reduced gradually, and almost eliminated at around 900 s. Subsequently, the temperature distribution pattern was turned to be inversed at around $1500 \mathrm{~s}$ due to the continuous smoke extraction and the decrease of fire's HRR. From the string of temperature measuring points near southeast corridor, an obvious temperature gradient was found at $70 \mathrm{~m}$ (approximately F22) during the whole test period, which indicates that the hazardous degree of smoke was remarkably different above and below this height. It should be paid enough attention on that the evacuation condition of corridor above F22 was much worse.

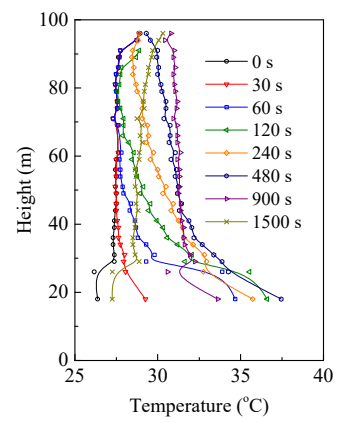

Fig. 9. Transient temperature right above the fire.
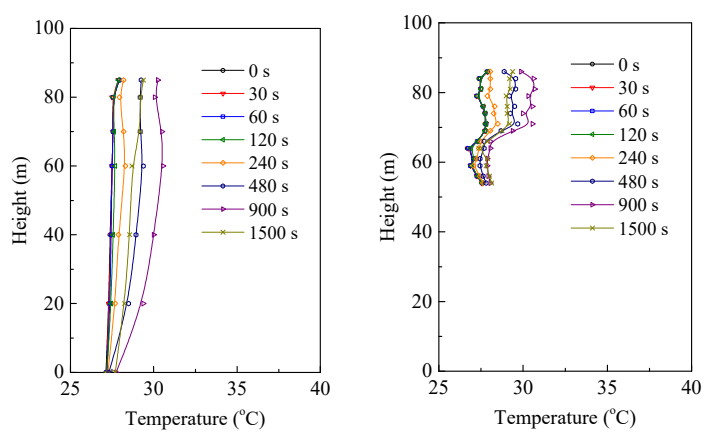

(a) Near southwest corridor (b) Near southeast corridor

Fig. 10. Temperature distribution in typical moments in the atrium (with mechanical smoke extraction process)

Based on the classic plume model developed by Zukoski [15], the flow rate of smoke plume at the height of $z$ from an ideal point fire source is

$$
\dot{m}_{p}=0.20\left(\frac{\rho_{\infty}^{2} g}{c_{p} T_{\infty}}\right)^{1 / 3} \dot{Q}^{1 / 3} z^{5 / 3}
$$

Assume there is no radiation heat loss from the plume to the environment, then

$$
\dot{Q}=\dot{m}_{p} c_{p} \Delta T
$$

Substitute Eq. (2) into Eq. (1), and the average temperature increase in the smoke plume center at different heights can be deduced as

$$
\Delta T=5.0\left(\frac{T_{\infty}}{g c_{p}^{2} \rho_{\infty}^{2}}\right)^{1 / 3} \dot{Q}^{2 / 3} z^{-5 / 3}
$$

As shown in Eq. (3), the temperature increase in the smoke plume is linear with the $(-5 / 3)$ power of height. Plot the test results and the calculation results from Eq. (3) together in Fig. 11(a), and they are well matched. The deviation of the region near fire is a little larger, which may be caused by the difference between real 
ethanol pool fire and simplified point source. However, most of the data is accumulated near the origin of axis, so plot the data above $49 \mathrm{~m}$ (the height of one of the temperature measuring points) separately in Fig. 11(b) in order to zoom in. It can be seen from the figure that when the height is over $60 \mathrm{~m}$, i.e. above the plume touching point, the existing linear trend is broken and the temperature increases in the smoke plume are significantly lower than the theoretical prediction ones, which verifies the enhancement effect of boundary heat exchange caused by plume restriction in ultra thin and tall atriums.

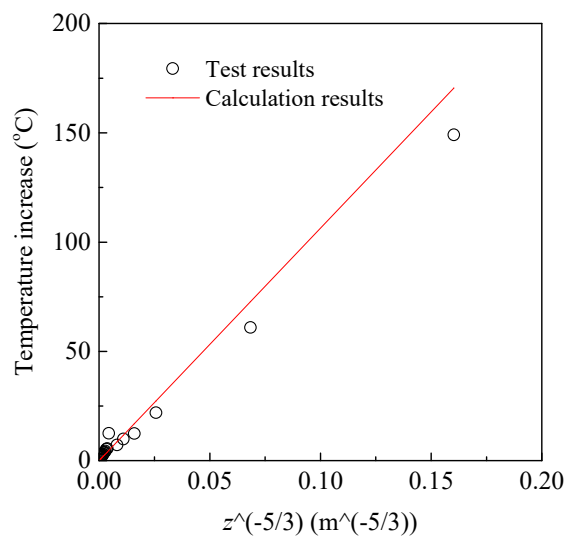

(a) $\mathrm{z}=3 \sim 96 \mathrm{~m}$

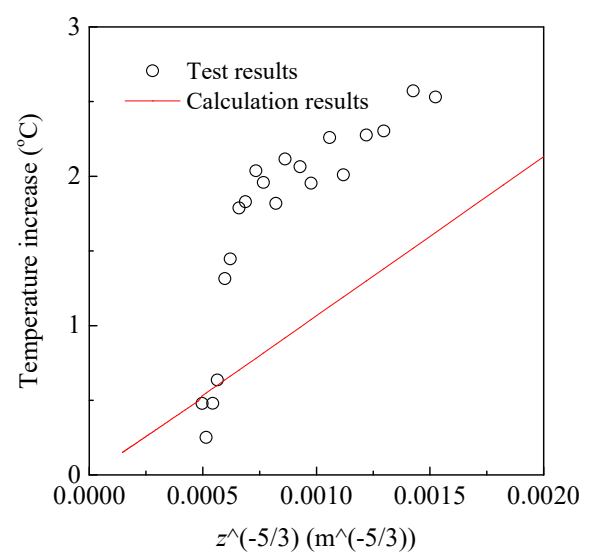

(b) $\mathrm{z}=49 \sim 96 \mathrm{~m}$

Fig. 11. The comparison on plume center temperature differences of test results and calculation results by Zukoski model.

\subsection{Smoke density distribution in the atrium}

Fig.12 shows the sampled smoke density change over time during the entire test. The fluctuation of smoke density curve decreased with the rise of the floor, and the F26d had a nearly smooth one, indicating that the stratification state of smoke at the top of the ultra tall and thin atrium was stable. The horizontal sampling smoke density reflected that in the very early stage of natural filling the highest smoke concentration appeared near the height of the wall touch point, higher than the top, and it maintained at a high level in the middle and late stages. This height will be the first area attacked by smoke in an atrium fire and is the ideal location for fire detection. As the installation position was close to the wall, the smoke density measured by vertical sampling tube was stable and low. The current Chinese standard demands that the vertical sampling tube should be set at the same time with horizontal one in high-large spaces when aspirating sampling system is used. The reasonability and applicability of this provision in ultra thin and tall atriums needs more research and fire tests verification.

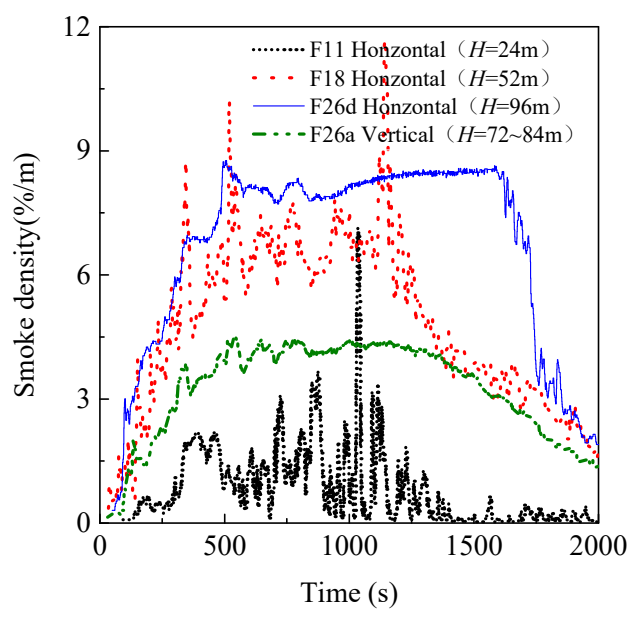

Fig. 12. Transient smoke density of different sample positions

\subsection{Relations between smoke density and smoke temperature for hot smoke test}

Smoke density is the key parameter which is directly related to the hazardous degree. But in the practical tests, the smoke density is difficult to measure while the temperature data is relatively easy to obtain. Therefore, it is necessary to correlate the smoke density and temperature in the hot smoke test.

When comparing the smoke density with the corresponding temperature data at the same positions, the variation tendencies of these two parameters are almost the same, and the hysteresis phenomenon of temperature can be found. For smoke density, there are plateaus around the peaks, especially on F26d, which is different from the temperature. Correlate these two parameters during the simultaneous increase and decrease stages and good linear relations can be observed, as shown in Fig. 13. As a result, during the smoke natural filling process of hot smoke test, it is feasible to reflect the smoke concentration distribution by the temperature distribution. 


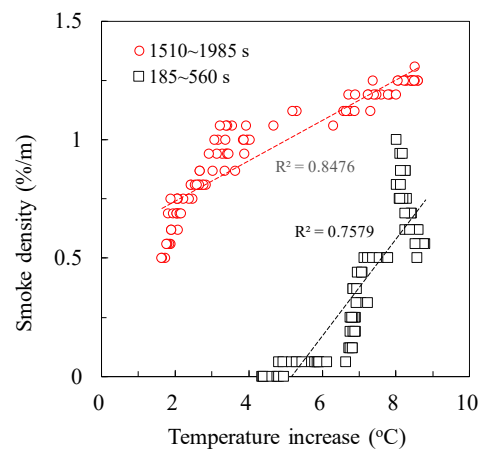

Fig. 13. Relation of the smoke density and the corresponding temperature during the simultaneous increase and decrease stages.

\subsection{Dimension criterion of ultra thin and tall atrium}

Considering the restriction phenomenon of smoke plume filling in the ultra thin and tall atriums, the definition of such type of atriums needs to be further discussed. Shown as Fig. 2, the noncentral fire leaded to the asymmetry of smoke plume restriction, and two critical restriction conditions of ideal 2-D noncentral fire are given in Fig. 14.
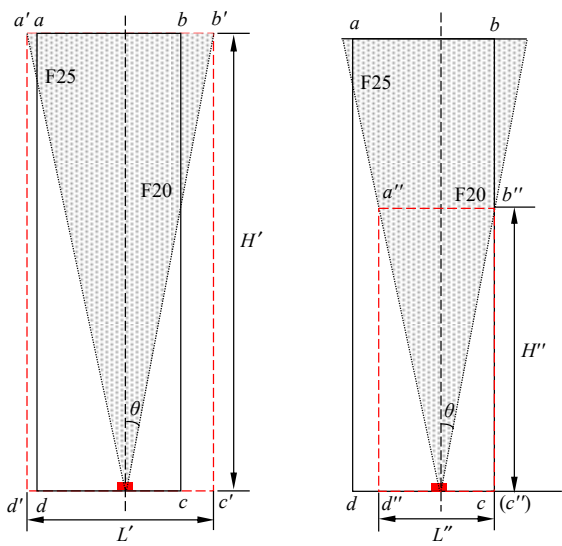

(a) Horizontal restriction dimension (b) Vertical restriction dimension

Fig. 14. Critical restriction dimensions for the noncentral fire in an ideal 2-D atrium.

The pool fire is simplified as point source, and the plume boundaries are simplified as equicrural triangle, thus the smoke plume will initially touch the side wall which is closer to the fire. In Fig. 14(a), keep the atrium height unchanged and extend the plume boundaries naturally, and the critical restriction boundaries are formed when intersecting at $a^{\prime}, b^{\prime}$ (ceiling height). Similarly in Fig. 14(b), keep the distance between the fire and the closer side wall unchanged, then reduce the atrium height till the lower touching point, and the other critical restriction boundaries could be obtained. Clearly, we can have

$$
\frac{\left|a^{\prime} b^{\prime}\right|}{\left|b^{\prime} c^{\prime}\right|}=\frac{\left|a^{\prime \prime} b^{\prime \prime}\right|}{\left|b^{\prime \prime} c^{\prime \prime}\right|}=2 \tan \theta
$$

Deducing from smoke plume formula of ideal point source fire [16], we can have

$$
\tan \theta=\sqrt{\frac{2}{q}}
$$

Where $q$ is an undetermined constant independent of HRR. As for the fire located right at the center of atrium ground, the dimension criterion of ultra thin and tall atrium should be

$$
\zeta=\frac{1}{2 \tan \theta} \geq \sqrt{\frac{q}{8}}
$$

A few scholars have obtained the value of $q$ by experimental methods [17-20], as shown in Table 2, and

\begin{tabular}{|c|c|c|c|}
\hline Year & Scholar & $q$ & $\zeta$ \\
\hline 1941 & Schmidt & 45 & 2.37 \\
\hline 1953 & Rouse & 96 & 3.46 \\
\hline 1956 & Morton & 80 & 3.16 \\
\hline 1961 & Шепелев & 75 & 3.06 \\
\hline 1977 & George & 55 & 2.62 \\
\hline 1986 & Turner & 100 & 3.54 \\
\hline 1990 & Kofoed & 110 & 3.71 \\
\hline \multicolumn{2}{|c|}{ Avg. } & 80.14 & 3.13 \\
\hline \multicolumn{2}{|c|}{ Std dev. } & 22.14 & 0.45 \\
\hline
\end{tabular}
$\zeta$ ranges from 2.37 to 3.71 .

Table 2. Dimension criterion of ultra thin and tall atrium.

The heights of touching points measured in the test as well as the calculated $\zeta$ are given in Table 3 .

Table 3. Heights of touching points and calculated $\zeta$.

\begin{tabular}{|c|c|c|c|}
\hline Test No. & $\begin{array}{c}\text { Distance } \\
\text { between fire } \\
\text { and closer side } \\
\text { wall (m) }\end{array}$ & $\begin{array}{c}\text { Height of } \\
\text { touching point } \\
(\mathbf{m})\end{array}$ & $\boldsymbol{\zeta}_{\text {test }}$ \\
\hline 1 & 10 & 60 & 3.0 \\
\hline $\begin{array}{c}\text { 2 (Repeated } \\
\text { trail) }\end{array}$ & 10 & 68 & 3.4 \\
\hline Avg. & 10 & 64 & 3.2 \\
\hline
\end{tabular}

It can be found that the $\zeta$ obtained from the test is very close to the theoretical one. Thus, considering the restriction of smoke plume on the most disadvantage condition (i.e. fire at the center of atrium ground), this value can be regarded as the lower limit of height-width ratio of ultra thin and tall atriums.

\section{Conclusions}

Based on the hot smoke test conducted in the ultra thin and tall atrium in TVCC hotel, here come the conclusions, summarized as below:

(1) The smoke plume touched the wall first and then extended both upwards and downwards, i.e. the adjacent floors above and below the touching point were more likely to be invaded by smoke even with the smoke barriers. It means spread mode of smoke in the ultra-thin high atrium changes from subsiding filling (first move to the top then subside) to upper and lower propagating filling (fill and subside after contact the side wall). In the very early stage of natural filling, the concentration of 
smoke near the height of wall touching point was highest and maintained at a high level during the whole process. The smoke subsided and spread circularly along corridors after reaching the top simultaneously, and the former could be well controlled by starting the extraction fans.

(2) In the ultra thin and tall atrium, the smoke plume rising velocity can be divided into four variation stages: accelerated near the fire source, decelerated before touching side wall, accelerated again after being restricted and eventually entered the deceleration zone at the top of the atrium.

(3) At the beginning of test, the temperature distribution right above the fire was lower on the bottom and higher on the top, and tended to be uniform around 900 s. With the activation of extraction fans and the decrease of fire's HRR, the temperature distribution pattern was turned to be inversed. The temperature distribution away from the fire indicated that the evacuation environment above the touching points was much worse. By the comparison of average temperature increase of smoke plume center, the enhancement effect of boundary heat exchange caused by plume restriction in ultra thin and tall atriums is verified.

(4) The variation tendencies of smoke density and temperature are almost the same, but there are hysteresis phenomenon of temperature comparing with smoke density, and the smoke density keeps almost unchanged in the middle of the test. There is a good linear relation between these two parameters during the smoke natural filling process.

(5) The dimension criterion of ultra thin and tall atrium is deduced, and it is proved that the test result is quite close to the theoretical calculation one. When the height-width ratio of atrium is more than 3.2, the smoke plume can possibly touch the wall and hence such atrium can be regarded as ultra thin and tall atrium.

\section{Acknowledgment}

The work was supported by CABR Application Technology Research Project: Key Technology of Smoke Control for Ultra Thin and Tall Atriums (No. 20150111330730049)

\section{References}

1. H.W.Zhang. The Worry of Rapid Expansion of Skyscrapers in China, Residence and Estate 2, p. 48(2014)

2. W. Chow, W. Wong. A study of the fire aspect of atria in Hong Kong. Fire Safety Science 3: 335344(1991)

3. W. Chow. Simulation of the atrium fire environment in Hong Kong, Ashrae Transactions 99, p. 163-168 (1993)

4. J.H. Klote, J.A. Milke. Principles of smoke management (2002).

5. Standard for Smoke control Systems. NFPA92(2015)
6. T. Naruse, S.Sugahara. Some investigations on fire safety design for atriums. Journal of Structural \& Construction Engineering, 443: 147-157(1993)

7. F.Liu. Studies on smoke movement and smoke management in atrium fire.Chongqing University (2002)

8. H.Zhang, H.Wang, C.Du, L.Li, J.Jiang. Analysis on the prediction methods of natural filling smoke layer height in ultra-thin atrium, Fire Science and Technology 5, p. 617-620(2017)

9. H.Satoh, O.Sugawa, H.Kurioka. Flame inclination with induced wind through inlet opening in a tall and narrow atrium(1997)

10. W.Chow. Performance-based approach to determining fire safety provisions for buildings in the Asia-Oceania regions. Building \& Environment, 91: $127-137(2015)$

11. Smoke management system-Hot smoke test. AS4391-1999

12. Test method for verifying field performance of smoke management system-Hot smoke test.GA/T 999-2012

13. B. Atkinson.HST verification of smoke management systems using the Australian method. EUROFIRE 99 Conference(Belgium, 1999)

14. Y.Li, G. Wang, L.Li, D.Wang, L. Han, H.Yu, D.Liu. Post-Fire Performance Evaluation Method of HighRise Buildings and its Applications in TVCC, Building Science 11, p. 65-70(2014)

15. E.Zukoski,T.Kubota, B.Cetegen.Entrainment in Fire Plumes, Fire Safety Journal 3, p. 107-121(1981)

16. H.Zhao.Indoor heat convection and ventilation, China Architecture \& Building Press, Beijing, p.2733(2010).

17. И.Шепелев. Indoor aerodynamics (in Chinese), (1960)

18. P.Kofoed, P.V.Nielsen.Thermal plumes in ventilated room. Aalborg university,Danmark(1988)

19. H.Skistad,E.Mundt,V.P.Nielsen,K.Hagström, J.Railio. Displacement ventilation in non-industrial premises, Guidebook No.1, FEHVA, Belgium (2002)

20. G.Hunt,P.Cooper, P.Linden.Thermal stratification produced by plumes and jets in enclosed spaces, Building \& Environment 7, P. 871-882(2001). 